\title{
Photochemistry of Rhenium(I) Diimine Tricarbonyl Complexes in Biological Applications
}

\author{
Kevin Schindler and Fabio Zobi ${ }^{\star}$
}

\begin{abstract}
Luminescent rhenium complexes continue to be the focus of growing scientific interest for catalytic, diagnostic and therapeutic applications, with emphasis on the development of their photophysical and photochemical properties. In this short review, we explore such properties with a focus on the biological applications of the molecules. We discuss the importance of the ligand choice to the contribution and their involvement towards the most significant electronic transitions of the metal species and what strategies are used to exploit the potential of the molecules in medicinal applications. We begin by detailing the photophysics of the molecules; we then describe the three most common photoreactions of rhenium complexes as photosensitizers in $\mathrm{H}_{2}$ production, photocatalysts in $\mathrm{CO}_{2}$ reduction and photochemical ligand substitution. In the last part, we describe their applications as luminescent cellular probes and how photochemical ligand substitution is utilized in the development of photoactive carbon monoxide-releasing molecules as anticancer and antimicrobial agents.
\end{abstract}

Keywords: Cellular probes $\cdot$ Rhenium $\cdot$ Photocatalysis $\cdot$ Photochemistry $\cdot$ PhotoCORMs

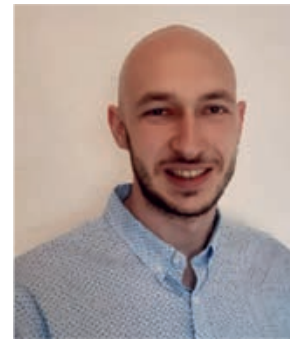

Kevin Schindler studied chemistry at the University of Fribourg and graduated in 2018 with a Bachelor's degree. In 2019, he joined the Zobi Group for his Master thesis, which he completed in 2020 and was among the students nominated for the Faculty Prize. In 2021, he started his PhD studies in the group. His work focuses on new stable diamagnetic rhenium species capable of acting as synthons for the preparation of a variety of new complexes. The research program aims at understanding the fundamental chemistry of these new species with different supporting chelating ligands.

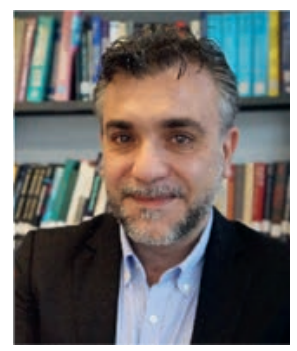

Fabio Zobi studied biochemistry at the York University, Canada, where in 2001 he received a Master in inorganic chemistry. He completed his $\mathrm{PhD}$ at the University of Zurich in 2005 under the direction of Roger Alberto. After a postdoctoral stay at the University of Edinburgh he moved back to Zürich as a postdoctoral researcher holding a SNF-Ambizione fellowship. In 2013, he moved as an SNF professor to the University of Fribourg, where he was promoted as an associate professor in 2017. His research interests are diverse covering different topics in inorganic and organometallic medicinal chemistry, mainly of group 7 elements.

\section{Introduction}

The use of luminescent transition metal complexes is of great scientific importance for the development of various sensors, ${ }^{[1]}$ probes $^{[2]}$ and catalysts ${ }^{[3]}$ that allow the community to address very different bio/chemical questions and problems. Due to their photophysical and photochemical properties, diimine species of rhenium tricarbonyl complexes are among the most widely studied metal-based luminophores in biological applications. ${ }^{[4]}$ Such complexes show intense emission at moderate temperature, photochemical stability and easy adjustability of their photophysical properties by altering the electronic properties of the supporting ligands in their coordination sphere. ${ }^{[5]}$ In addition, due to their synthetic flexibility and stability, as well as their long-lived excited states and strong photoluminescence, these rhenium-based complexes generate suitable electron-transfer sensitizers. ${ }^{[6]}$ These compounds combine diagnostic and therapeutic purposes and show promising anticancer and antimicrobial potential. ${ }^{[4]}$ Several such rhenium diimine complexes are efficient photosensitizers producing singlet oxygen under physiological conditions and are investigated in photodynamic therapy (PDT) alongside other metal ions like ruthenium. ${ }^{\left[{ }^{[8]}\right.}$ Moreover, the presence of the carbon monoxide ligands can lead the complexes, if suitable photo and chemical conditions are met, to $\mathrm{CO}$ release and delivery to selective locations within organs and tissues, and the molecules are often evaluated against malignant neoplacias in the everlasting fight against cancer. ${ }^{[9]}$

In this short review, we address the basic photophysical properties of the rhenium(I) diimine complexes molecules, highlighting the most significant electronic transitions of these complexes, the orbitals involved, and the contribution of each ligand in determining both the luminescence features, the cellular localization and the photo-reactivity of the molecules. We start with basic inorganic principles to develop a discussion leading to their applications as luminescent cellular probes and, in particular, to the photochemical ligand substitution (PLS) reactions and how this reactivity is currently being investigated as an alternative strategy for the preparation of new therapeutic rhenium 'pro-drugs'. We also briefly describe the other two most common photoreactions of rhenium complexes as photosensitizers in $\mathrm{H}_{2}$ production and as photocatalysts in $\mathrm{CO}_{2}$ reduction.

\section{Photophysical Properties of Rhenium(I) Diimine Complexes}

Diimine rhenium(I) tricarbonyl complexes may undergo several electronic transitions, of which the most relevant for their photophysical properties (and photochemistry) are simply referred to as the metal-to-ligand charge transfer (MLCT) and 
ligand field (LF) transitions. ${ }^{[10]}$ In reality, these transitions are mixed, with other states and each other, by configuration interactions. It is, however, useful in our discussion to refer to them in terms of the virtual pure state that has the largest contribution to the specific excited state properties. We will use this simplified terminology throughout the text. Typically, for complexes of formula $f a c-\left[\operatorname{Re}(\mathrm{CO})_{3}(\text { diimine }) \mathrm{X}\right]^{\mathrm{n}}$ (where diimine $=$ most frequently 2,2'-bipyridine or 1,10-phenanthroline, $\mathrm{X}=$ monodentate ligand and $n=0$ or +1 , Fig. 1), the highest occupied molecular orbital (HOMO) is of $>50 \%$ metal d-orbital character. The $\mathrm{CO}$ and $\mathrm{X}$ ligands (when $\mathrm{X}=$ halide) contribute equally for $c a .20 \%$ each of the remaining HOMO character. In complexes where $\mathrm{X}$ is not an halide, but a $\sigma$-donor or a weak $\pi$-acceptor (e.g. pyridine), only the CO ligands contribute $\sim 20 \%$ to the HOMO character. In all cases, the lowest unoccupied molecular orbital (LUMO) is of $>80 \%$ character in diimine ligand $\pi^{*}$-orbital. ${ }^{[1]}$

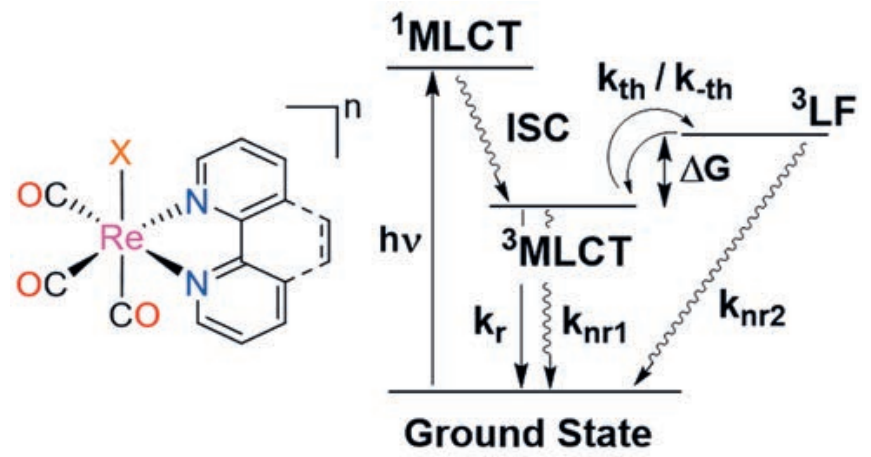

Fig. 1. Representative structure of a $\mathrm{fac}-\left[\operatorname{Re}(\mathrm{CO})_{3}(\text { diimine }) \mathrm{X}\right]^{\mathrm{n}}$ complex and corresponding MLCT model of the Jablonski diagram for the same. The $\mathrm{k}_{\mathrm{r}}$ and $\mathrm{k}_{\mathrm{nr}}$ are the radiative and nonradiative decay constants from the excited state to the ground state. The $\mathrm{k}_{\mathrm{th}}$ and $\mathrm{k}_{-\mathrm{th}}$ are respectively the forward and backward thermal activation rate.

In an octahedral environment, the metal d-orbitals split in the canonical $t_{2 g}-e_{g}$ set, with the latter at relatively high energy due to the strong LF induced by the CO's, resulting in a low-oxidation state of the central metal. The energy of the empty diimine $\pi^{*}$-orbital is low due to the conjugated $\pi$-system. The diimine $\pi^{*}$-orbital is, therefore, at a lower energy than the empty d orbital, making the ${ }^{1}$ MLCT state (more precisely the singlet metal-ligand to ligand charge transfer, ${ }^{1}$ MLLCT) the lowest excited state in the vast majority of cases (Fig. 1). ${ }^{[12]}$ The ${ }^{1}$ MLCT transition is optically allowed, it does not violate selection rules and has a relatively large transition moment. Since it formally involves only population of an orbital that is antibonding in the diimine ligand, but not in terms of the metal-ligand bonds, the complexes are photostable. The large spin-orbit (SO) coupling associated with the third-row metal ion allows for efficient intersystem crossing (ISC), ${ }^{[13]}$ allowing the ${ }^{1}$ MLCT to decay via vibrational relaxation to the excited triplet ${ }^{3}$ MLCT state, ${ }^{[14]}$ which is emissive (Fig. 1). This state is in thermal equilibrium with the ${ }^{3} \mathrm{LF},{ }^{[15]}$ which is responsible for the reactivity of the complexes if specific conditions are satisfied (vide infra). The emissive processes (related to the radiative constant $\mathrm{k}_{\mathrm{r}}$ in Fig. 1) is strictly spin-forbidden (going to a singlet ground state), and the $\mathrm{k}_{\mathrm{r}}$ value for emitters from triplet states depends on the SO coupling according to Eqn. (1):[16]

$$
\mathrm{k}_{\mathrm{r}} \approx\left({ }^{1} E_{3}\right)^{3} \sum_{i} \frac{\left\langle{ }^{1} \varphi_{\mathrm{i}}\left|H_{S O}\right|^{3} \varphi 1\right\rangle}{{ }^{1} E_{i}-{ }^{3} E_{1}} \frac{{ }^{1} f_{i}}{{ }^{1} E_{i}}
$$

where ${ }^{1} \varphi_{\mathrm{i}}$ and ${ }^{3} \varphi_{\mathrm{i}}$ and ${ }^{1} E_{\mathrm{i}}$ and ${ }^{3} E_{1}$ are the wavefunctions and energies, respectively, of the singlet excited states $S_{i}$ and of the lowest triplet excited state $\mathrm{T}_{1},{ }^{1} f_{\mathrm{i}}$ is the oscillator strength of the singlet-singlet excitations, and $H_{\mathrm{SO}}$ is the spin-orbit coupling operator.

The photophysical and photochemical properties of the complexes are largely determined by the nature of the diimine ligand acting as the electron pool via the $\pi^{*}$-orbitals. In solution, the complexes are often highly luminescent, exhibit relatively long lifetimes of emission (10 ns to $1 \mu \mathrm{s})$, large Stokes shifts and resistance to photobleaching. The complexes have also been described as showing a large hypsochromic shift of their emission maxima in more rigid media or environments, a phenomenon referred to as luminescence rigidochromism. ${ }^{[17]}$ The shift in the emission maxima is a result of the increased energy of the long-lived ${ }^{3}$ MLCT due to the limited capacity of solvent molecules to reorient and stabilize the excited-state dipole moment. ${ }^{[18]}$ Shifts in the absorption and emission maxima of the species are also influenced by the $\pi$-character of the monodentate ligand $\mathrm{X}$ and interligand interactions.

Strong $\pi$-acid ligands can induce bathochromic shifts by destabilizing the HOMO level. ${ }^{[19]}$ Similarly, interligand $\pi-\pi$ interactions between the aromatic diimine ligand and the aryl substituents in $\mathrm{PR}_{3}$ ligands play a significant role in modulating the photophysical properties of the complexes. Such interactions, observed both in solution and the solid state, ${ }^{[20]}$ can be interpreted as 'rigidifying' the complexes, thereby decreasing $\mathrm{k}_{\mathrm{nr}}$ (the nonradiative decay rate constant) from the ${ }^{3}$ MLCT excited state and prolonging the excitation lifetime. Ishitani suggested that interligand $\pi-\pi$ interactions result in a decrease of the lateral displacement $\Delta \mathrm{D}_{\mathrm{e}}$ associated with the absorption and emission wavelengths and can be rationalized by the energy surfaces shown in Fig. 2.[19] $\pi-\pi$ interactions can increase excited electron delocalization onto the diimine ligand (considering either ${ }^{1} \mathrm{MLCT}$ or ${ }^{3} \mathrm{MLCT}$ excited states) rendering the excitation process less energetically demanding. The net result is that the ${ }^{3}$ MLCT-excited state can emit a higher-energy photon and that the absorption and emission shift respectively to longer and shorter wavelengths. Finally, the smaller $\Delta \mathrm{D}$, value gives a smaller Franck-Condon factor, that is, a smaller $\mathrm{k}_{\mathrm{nr}}$, resulting in an increase of the excitation lifetime.
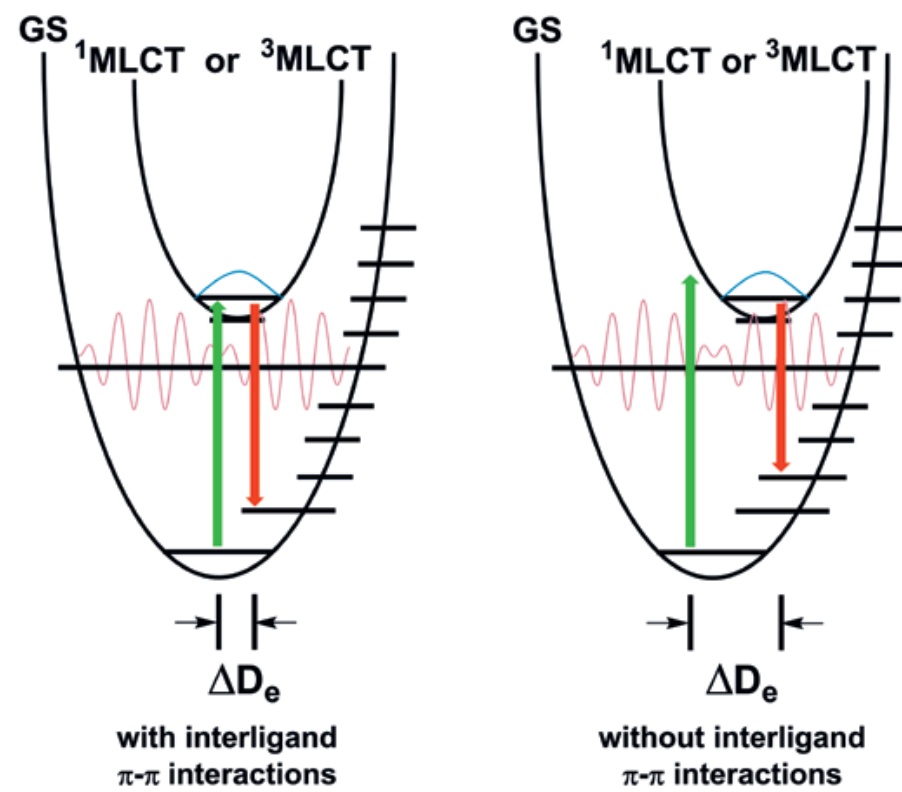

Fig. 2. Energy surfaces of the ground state (GS) and the ${ }^{1} \mathrm{MLCT}$ or ${ }^{3}$ MLCT excited states as a function of the interligand $\pi-\pi$ interaction. Figure readapted with permission of Publisher. ${ }^{[19]}$

\section{Photochemistry of Rhenium( $($ ) Diimine Complexes}

The photochemistry of tricarbonyl rhenium(I) diimine complexes is mainly associated with their role as a) photosensitizers 
in the electron transfer step to water reduction catalysts in $\mathrm{H}_{2}$ production; ${ }^{[21]}$ b) catalysts in the photoinduced reduction of carbon dioxide to carbon monoxide; ${ }^{[22]}$ and c) photoreactions leading to carbon monoxide dissociation for synthetic and biological applications. The photocatalytic activity of the complexes is of tremendous importance, and a subject actively investigated in light of the environmental and societal challenges associated with energy storage and production. In both these applications, the excited reduced state of the molecule plays a key role.[23] Fig. 3 depicts the fundamental steps in these cycles. The lowest excited state of the rhenium complexes in the photocatalytic reactions is almost invariably the ${ }^{3} \mathrm{MLCT}$ state. ${ }^{[24]}$ Following photo-excitation, the rhenium diimine complex ( $\mathbf{A}$ in the figure) accepts an electron from a sacrificial electron donor generating the excited one electron reduced (OER) species B. Species B may act as a photosensitizer, conveying the electron to a water reduction catalyst, which in turn relays it to protons for the formation of the $\mathrm{H}-\mathrm{H}$ bond. ${ }^{[25]}$ Under different experimental conditions, the complex binds to $\mathrm{CO}_{2}$ following dissociation of the ancillary monodentate ligand (most often an anion) via the pentacoordinated complex C. The active species formed by elimination of the ancillary ligand, is formally a 17-electron complex that reacts with $\mathrm{CO}_{2}$ to generate the corresponding $\mathrm{CO}_{2}$ adduct. The structure of the $\mathrm{CO}_{2}$ adduct, which is a key intermediate in the photocatalysis, has not yet been unambiguously confirmed but a rhenium carboxylate complex ${ }^{[26]}$ of general formula $f a c-\left[\operatorname{Re}(\mathrm{CO})_{3}(\mathrm{~N}-\mathrm{N})(\mathrm{COOH})\right]$ and a CO -bridged binuclear $\left[(\mathrm{CO})_{3}(\mathrm{~N}-\mathrm{N}) \mathrm{Re}-\mathrm{CO}_{2}-\mathrm{Re}(\mathrm{N}-\mathrm{N})(\mathrm{CO})_{3}\right] \mathrm{di}-$ mer $^{[27]}$ have been proposed and synthesized. For the mechanism of carbon dioxide reduction, these mononuclear or binuclear intermediate are most often invoked.

The mechanisms of $\mathrm{CO}_{2}$ reduction depend strongly on the nature of the monodentate ligand, with phosphine complexes associated more to a multicomponent system. ${ }^{[28]}$ With anionic ligands, the rate of elimination of the same from the one-electron reduced species $\mathbf{B}$ dictates the photocatalytic abilities of the complexes. Exchange of halides such as $\mathrm{Cl}^{-}$is relatively fast and only small concentrations of OER are detected under standard photocatalytic conditions. ${ }^{[28]}$ With slower eliminating ligands such as $\mathrm{SCN}^{-}$, the photocatalytic reaction proceeds with relatively high accumulation of the OER in solution. The longer lifetime of the OER allows its detection but at the same time, the persistent presence of the species produces an inner filter effect lowering the apparent quantum yield of $\mathrm{CO}$ production. Rhenium complexes for which the corresponding OER species rapidly exchange $\mathrm{X}^{-}$are reported to convert to the carboxylate complex $f a c-\left[\operatorname{Re}(\mathrm{CO})_{3}(\mathrm{~N}-\mathrm{N})\right.$ $(\mathrm{COOH})$. $^{[23,24]}$ Complexes bearing stronger ligands, such as $\mathrm{CN}^{-}$, show no photocatalytic behaviour, an observation understood on the basis that the OER does not eliminate the $\pi$-acid ligand, thus preventing formation of $\mathbf{C}$ in the next step of the catalytic cycle. ${ }^{[28]}$ In photocatalytic reactions only one-electron transfer can occur with one photon. Two electrons cannot be concurrently added to the complex, but this can be achieved electrochemically. Under such conditions, similar cycles and structures for the ' $\mathrm{CO}_{2}$ adduct' have been proposed. ${ }^{[29]}$

The third type of photoreaction commonly associated with rhenium tricarbonyl species, and most relevant to the biological and medical applications of the molecules, is the photochemical ligand substitution (PLS) reaction. In order to understand the photoreaction it is important to understand the nature of the $\mathrm{Re}-\mathrm{CO}$ bond itself. Basic principles of inorganic chemistry are sufficient, but obviously, the picture is a simplified one as the atomic wave functions combine into molecular ones of different characters. Tricarbonyl rhenium(I) diimine complexes almost invariably show an octahedral (often slightly distorted) geometry. The ligand field (LF) d-orbital splitting of the Re atom is $t_{2 g}-e_{g}$ with all six d-electrons formally occupying the former. The presence of the strong $\pi$-acid ligand $\mathrm{CO}$, renders the $\mathrm{e}_{\mathrm{g}}$ set antibonding (i.e. $\mathrm{e}_{\mathrm{g}}^{*}$ ), stabilizes the $t_{2 g}$ energy, thereby increasing the d-orbital energy gap and producing a strong LF. The coordination bond between Re atom and $\mathrm{CO}$ is archived by $\sigma$-donation from the lone pair electrons of $\mathrm{CO}$ to the $\mathrm{e}_{\mathrm{g}}^{*}$ set and $\pi$-back donation from $\mathrm{t}_{2 \mathrm{~g}}$ electron to the $\pi^{*}$ orbitals of ${ }^{\mathrm{g}} \mathrm{CO} \cdot{ }^{[30]}$ This interaction increases the Re-C bond order (formally $>1$ ) while decreasing the same for the $\mathrm{C} \equiv \mathrm{O}$ (formally $<3$ ), thus resulting in a robust $\mathrm{Re}-\mathrm{CO}$ bond.

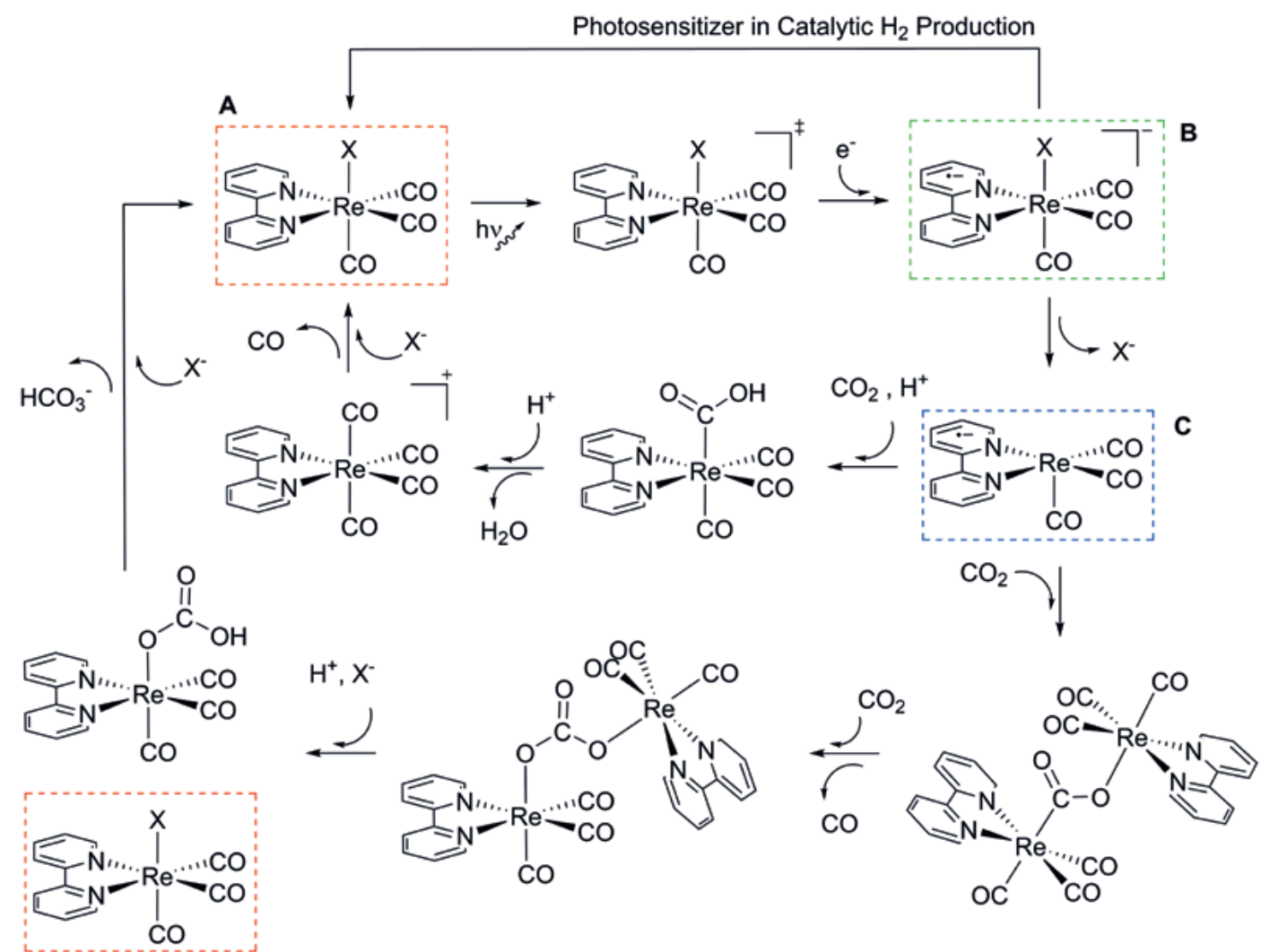

Fig. 3. Simplified scheme of the photocatalytic reactions involving tricarbonyl rhenium(I) diimine complexes in $\mathrm{H}_{2}$ production and $\mathrm{CO}_{2}$ reduction. 
When an N-N diimine ligand is added to the picture, the photoexcitation processes important to interpret the photoreactivity of the species, are the MLCT (metal-to-ligand charge transfer, Re $\mathrm{d}_{\pi}$ $\left.\rightarrow \pi^{*} \mathrm{~N}-\mathrm{N}\right)$ and the LF transition $\left(\operatorname{Re} \mathrm{t}_{2 \mathrm{~g}} \rightarrow \operatorname{Re}_{\mathrm{g}}{ }^{*}\right)$. The forbidden $\mathrm{LF}$ transition is responsible for the photochemical reaction as it involves excitation of $\mathrm{t}_{2 \mathrm{~g}}$ bonding electron into the antibonding $\mathrm{e}_{\mathrm{g}}{ }^{*}$ orbitals, weakening the Re-CO interaction and eliminating one CO ligand. ${ }^{[15]}$ Most rhenium tricarbonyl species can be considered as photochemically stable. It was, however, the report of the photochemical ligand substitution of $f a c-\left[\operatorname{Re}(\mathrm{N}-\mathrm{N})(\mathrm{CO})_{3}\left(\mathrm{PR}_{3}\right)\right]^{+}$ (where $\mathrm{PR}_{3}=$ triethylphosphite) that allowed the exploitation of the reaction for synthetic and, eventually, for bio-medical applications. ${ }^{[31]}$ When a $\mathrm{PR}_{3}$ complex is irradiated in coordinating solvents, the $\mathrm{CO}$ ligand trans to $\mathrm{PR}_{3}$ is selectively eliminated via a dissociative mechanism and replaced by a solvent molecule $\mathrm{S}$, giving the corresponding cis-trans- $\left[\mathrm{Re}(\mathrm{N}-\mathrm{N})(\mathrm{CO})_{2}\left(\mathrm{PR}_{3}\right)(\mathrm{S})\right]^{+}$. Acetonitrile is the solvent of choice in these reactions, but similar water and halide complexes have been reported. ${ }^{[32]}$ Transient IR absorption (TR-IR) measurements, have revealed that the absorption intensities of the product IR bands are proportional to the amount of the ${ }^{3}$ MLCT state complex generated instantly after irradiation, ${ }^{[15]}$ suggesting that PLS proceeds either from the ${ }^{3}$ MLCT state or the ${ }^{3} \mathrm{LF}$ state, which are in thermal equilibrium (Fig. 4).

The energy levels of these states can be modified respectively by electron donating or withdrawing groups on the N-N diimine ligand (resulting in either a destabilization or stabilization of the $\pi^{*} \mathrm{~N}-\mathrm{N}$ orbital) or by replacement of the monodentate ligand coordinated to the Re atom. ${ }^{[33]}$ Strong LF ligands, such as the $\pi$-acid $\mathrm{PR}_{3}$, stabilize the rhenium $\mathrm{d}_{\pi}$ orbitals and destabilize the rhenium $\mathrm{d}_{\sigma}{ }^{*}$ orbitals, while $\pi$-base ligands, such as hydroxide or halides, have the opposite effect. The latter ligands reduce the energy gap of LF transition $\left(\operatorname{Re} t_{2 g} \rightarrow \operatorname{Re}_{\mathrm{g}}{ }^{*}\right)$, but under similar experimental conditions complexes with $\pi$-basic or $\sigma$-donating ligands do not undergo PLS. Furthermore, it was shown that the thermal energy gap $\left(\Delta \mathrm{G}_{\#}{ }^{\ddagger}\right.$ in Fig. 4$)$ between ${ }^{3}$ MLCT and ${ }^{3} \mathrm{LF}$ states is in the same order of magnitude for all complexes (i.e. regardless of the nature of the monodentate ligand). ${ }^{[15]}$ The reason why $\mathrm{PR}_{3}$ complexes undergo PLS is attributed to a thermally accessible repulsive ${ }^{3} \mathrm{LF}$ (Fig. 4A), while for other species two explanations were originally formulated. ${ }^{[15]}$ With weak LF ligands, the thermal activation from ${ }^{3} \mathrm{MLCT}$ to ${ }^{3} \mathrm{LF}$ is preferable, but the ${ }^{3} \mathrm{LF}$ energy surface is not repulsive implying a large activation energy $\left(\Delta \mathrm{G}_{2}\right.$, in Fig. 4B) for CO elimination. Alternatively, the ${ }^{3} \mathrm{LF}$ state is thermally inaccessible from the ${ }^{3} \mathrm{MLCT}$ at room temperature $\left(\Delta \mathrm{G}_{3}\right.$, in Fig. $4 \mathrm{C})$. However, given that the thermal ${ }^{3} \mathrm{MLCT}-{ }^{3} \mathrm{LF}$ energy gaps are similar for all complexes, the following interpretation is generally accepted. Although the potential energy curves of the ${ }^{3}$ MLCT and ${ }^{3} \mathrm{LF}$ states cross each other in a relatively low-energy region, the trans-labilising effect of $\pi$-acids it is necessary to weaken the $\mathrm{Re}-\mathrm{CO}$ bond and overcome the higher-potential barrier for bond rupture.

This picture has been more recently refined and generalized for tricarbonyl rhenium diimine complexes with $\pi$-basic ligands. ${ }^{[34]}$ Mechanistic studies and picosecond time-resolved IR measurements indicate that in these complexes only irradiation with higher energy photons can induce photochemical ligand substitution reactions via higher energy vibrational states rather than the lowest-lying ${ }^{3} \mathrm{MLCT}$ excited or thermally accessible ${ }^{3} \mathrm{LF}$ states. These higher vibrational levels are those of the ${ }^{1}$ MLCT state and/or higher electronic excited state(s) including $\mathrm{Re} \rightarrow$ bpy and $\mathrm{Re} \rightarrow \mathrm{CO}{ }^{1} \mathrm{MLCT}$ transitions. Thus, excitation by high-energy light of $f a c-\left[\operatorname{Re}(\mathrm{N}-\mathrm{N})(\mathrm{CO})_{3}(\mathrm{~L})\right]^{\mathrm{n}}$ species (where $\mathrm{L}=\pi$-base or $\sigma$-donor ligand), leads to vibrationally hot photoproducts, which relax within 50-100 ps, while CO ligand dissociation occurs with subpicosecond rates after excitation.

\section{Cellular Probes}

Before the PLS reaction entered investigations within biological systems, tricarbonyl rhenium(I) diimine complexes have been exploited as infrared ${ }^{[35]}$ and luminescent ${ }^{[7 \mathrm{~d}, 36]}$ probes for cellular imaging studies. Complexes of the type $f a c-\left[\operatorname{Re}(\mathrm{CO})_{3}(\mathrm{~N}-\mathrm{N})(\mathrm{X})\right]^{\mathrm{n}}$ are amongst the most studied metal-based lumophores. Over 70 cellular imaging studies have revealed that in general, substituent variations of the diimine ligand will mainly influence the photophysical properties of the complexes with relatively little influence on the cellular uptake of the species, and minor effects on the localization of the same. Variations of the monodentate X ligand, on the other hand, can provide a degree of control of the uptake and intracellular accumulation of the agents. Charge and lipophilicity modulations are also effective in controlling the cellular uptake and distribution of the complexes, ${ }^{[37]}$ with wide variations observed. Most often, however, the increased lipophilicity of the diimine ligand improves cellular uptake via passive diffusion. ${ }^{[38]}$ It is currently not possible to predict what specific cellular compartments will be stained by the rhenium-based lumophores as a function of modification of charge, lipophilicity or X, unless of course known targeting biomolecules are conjugated to the complexes. This bioconjugate strategy is particularly useful for tracking the complexes in tissues and cancers. Examples include the use of hyaluronic acids, ${ }^{[39]}$ neurotensin, ${ }^{[40]}$ biotin, ${ }^{[41]}$ fructose ${ }^{[42]}$ and glucose. ${ }^{[43]}$
Fig. 4. Energy vs Re-L distance of rhenium(1) diimine complexes (where $L=C O$ ), for the reactive (A) and the nonreactive PLS cases (B and $\mathbf{C})$. Diagram $\mathbf{B}$ shows a non-repulsive ${ }^{3} \mathrm{LF}$ energy surface, while diagram $\mathbf{C}$ illustrates a thermally inaccessible ${ }^{3}$ LF energy surface. Only the three lowest-lying electronic states are shown. Figure readapted with permission of Publisher. ${ }^{[15]}$
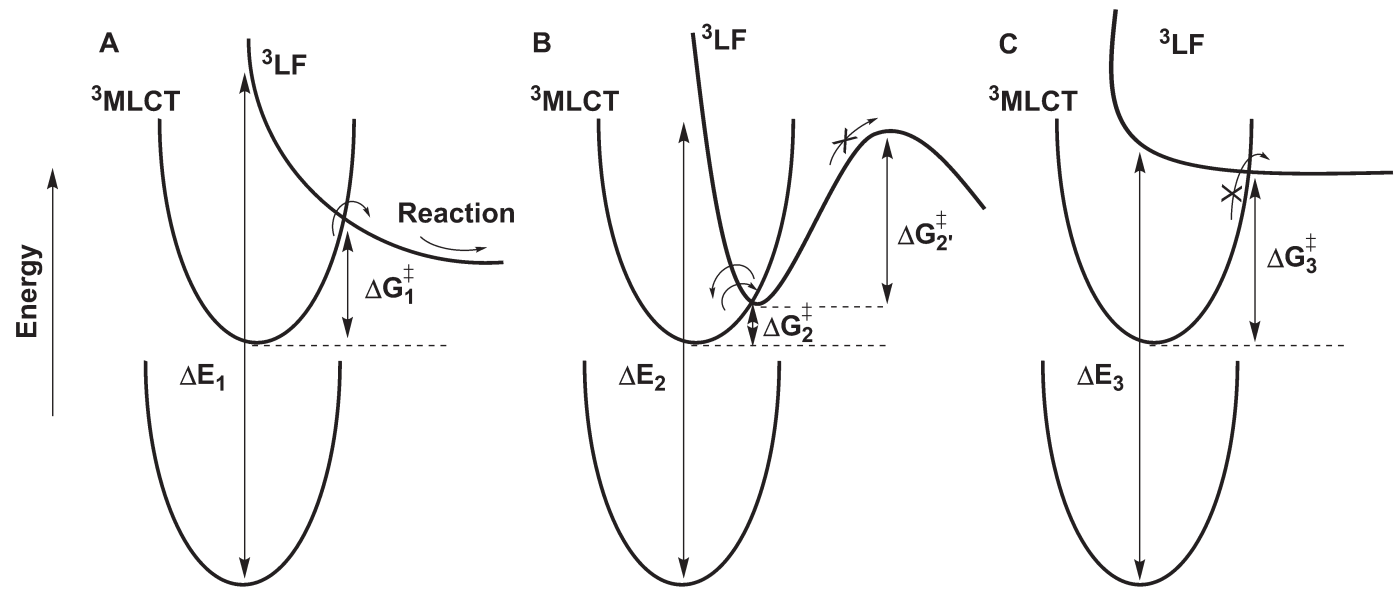
Coogan et al. described a cellular targeting strategy through covalent reactive-linker moieties of rhenium diimine 'pro-labels' that exemplifies how the monodentate ligand plays a crucial role for the cellular localization of the agents. ${ }^{[44]}$ By studying a series of diimine complexes with meta-derivatised pyridines (Fig. 5 ), the authors found that lipophilic complexes of pyridin-3-ylmethyl n-hydroxylalkynoates give different cellular localization patters due to accumulation in the cytoplasm and perinuclear regions with non-uniform staining of the cytosol.[44a] Removal of n-hydroxylalkynoates to the corresponding pyridin-3-ylmethanol resulted in luminescence detected exclusively in the perinuclear region. Based on these observations, the authors designed luminescent rhenium probes which could be chemically modified in vivo by mitochondria like commercial mitochondrial stains (e.g. the MitoTrackerR probe), which localise in membrane-bound cell organelles due to thiol-reactivity of a chloromethyl unit. Thus, the corresponding 3-(chloromethyl)pyridine rhenium diimine complex targets mitochondria by reacting with major mitochondrial thiol species like reduced glutathione (GSH). The resulting lipophilic impermeant thiol conjugate is trapped inside the organelles by the higher transmembrane potential for the inner mitochondrial membrane resulting in a highly specific stain. ${ }^{[44 b]}$
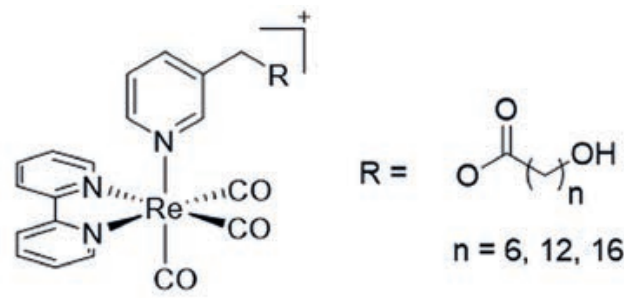

$n=6,12,16$
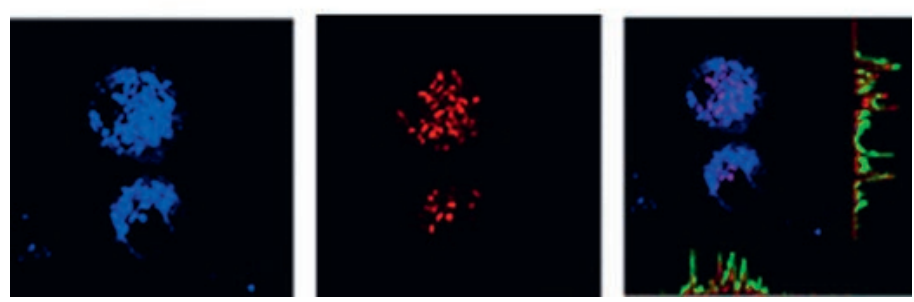

Fig. 5. Fluorescence images of MCF-7 cells incubated with the 3-(chloro methyl)pyridine derivative (i.e. with $\mathrm{R}=\mathrm{Cl}$, left), MitoTrackerR (centre) and overlaid images with intensity profiles. Figure reproduced with permission of Publisher. ${ }^{[45]}$

Another outstanding example of how the nature of the monodentate ligand influences the cellular localization of rhenium diimine complexes is represented by the set of derivatized tetrazolates of the tricarbonyl phenanthroline series. ${ }^{[46]}$ Massi et al. showed that modulation of the tetrazolate substituents influences the biological behaviour of the complexes in terms of cellular incubation and organelle specificity. ${ }^{[47]}$ They eventually prepared a 5-(pyridin-4-yl) tetrazol-2-ide derivative that localises in the endoplasmic reticulum (ER) with ideal live cell imaging properties (Fig. 6). ${ }^{[48]}$ This complex, now available under the trade name ReZolve-ER ${ }^{\mathrm{TM}}$, is resistant to photobleaching, shows consistent cellular localization, low cytotoxicity and compatibility with both single photon and two-photon excitation microscopy set-ups. ReZolve-ER ${ }^{\mathrm{TM}}$ rapidly internalizes intracellularly via a passive diffusion mechanism dependent on a concentration gradient. In different cell lines, it shows co-localization with ER-Tracker ${ }^{\circledR}$, and it is detected on the reticular network extending from the nucleus into the cytoplasm, with projections towards the nuclear membrane and on membranous structures extending into the nucleoplasmic reticulum. Furthermore, the complex allows the visualisation of specific nuclear events and ves- icle release from the cell surface, thus permitting investigation of a range of biological questions related to cellular dynamics (Fig. 6).
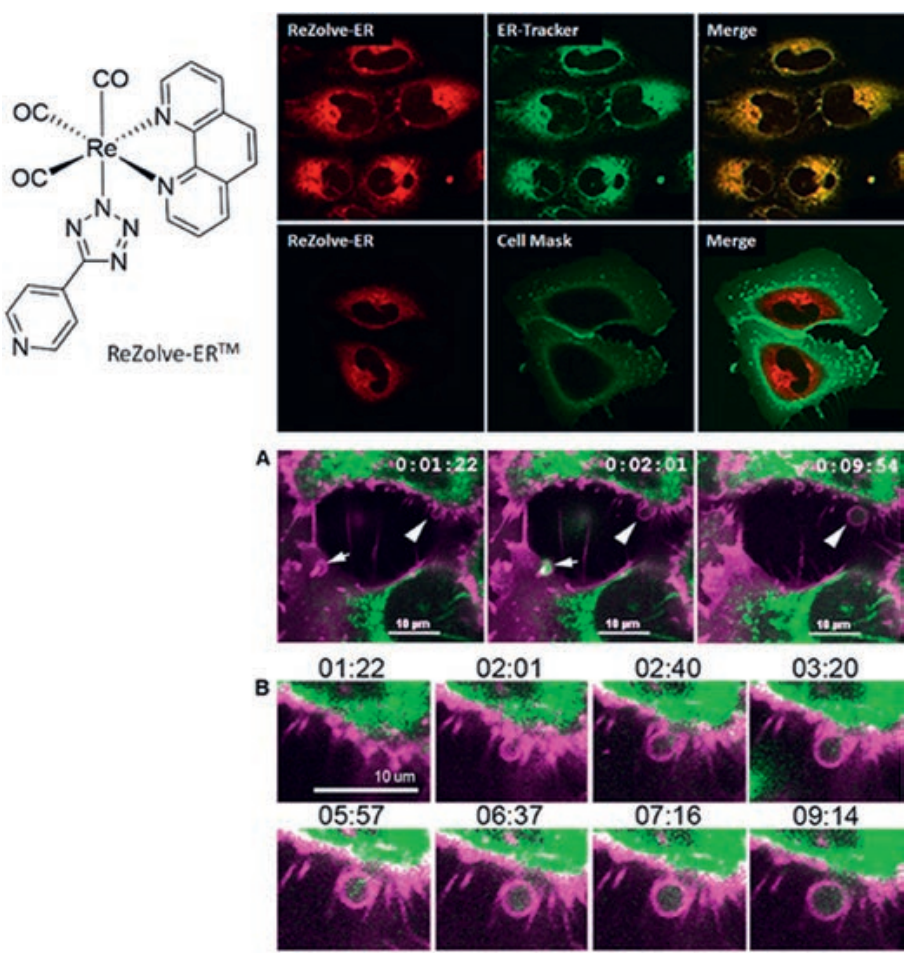

Fig. 6. Top: confocal micrographs showing PNT2 cells incubated with ReZolve-ER ${ }^{\mathrm{TM}}$ (red) and ER-Tracker ${ }^{\circledR}$ (green) and CellMask ${ }^{\mathrm{TM}}$ for the labelling of the plasma membrane (green). Bottom: Time lapse confocal micrographs showing PNT2 cells stained with ReZolve-ERTM (green) and counterstained with Cell Mask (purple) showing ReZolve-ERTM imaging of vesicle release from the cell surface. Figure reproduced and readapted with permission of Publisher. ${ }^{[48]}$

\section{Photoactive CO Releasing Molecules, Anticancer and Antimicrobial Complexes}

Rhenium tricarbonyl diimine complexes have been increasingly evaluated in the last two decades for their potential application in medicine. In the vast majority of cases, molecular species are investigated without probing their photoreactivity in the specific biological context. The molecules are particularly attractive as anticancer agents, ${ }^{[38,49]}$ but at the same time, they are progressively recognized as valuable antimicrobial drugs ${ }^{[50]}$ and cytoprotective $\mathrm{CO}$ releasing molecules. ${ }^{[35 a, 51]}$ Their mechanism of action remains largely unknown, but, as mentioned in the previous section, their photoluminescent properties can often aid with their cellular localization offering insights about specific targets. In line with the thematic issue, we will only discuss here rhenium diimine species whose biological activity has been probed as a function of their photoreactivity (i.e by exploiting the PLS reaction). One of the first examples of both a strongly luminescent and photoreactive carbon monoxide releasing tricarbonyl rhenium complex was introduced by Pierri et al. in 2012 (Fig. 7). ${ }^{[52]}$ The stable and non-toxic fac- $\left[\mathrm{Re}(\mathrm{bpy})(\mathrm{CO})_{3}\left(\mathrm{PR}_{3}\right)\right]^{+}$species (where $\mathrm{R}$ $=\mathrm{CH}_{2} \mathrm{OH}$ ) can penetrate into cells of human prostatic carcinoma, where its solvated product and $\mathrm{CO}$ can be generated photolytically. The solvated photoproduct is also luminescent, a feature that allows tracking both molecular transformations inside cells and its use as an imaginable reporter to indicate the location where $\mathrm{CO}$ is being delivered at the cellular scale. An important feature of the emission behaviour of the complexes, pertinent to biological applications, is the independence of the emission intensities and lifetimes ( $\mathrm{ca} .400 \mathrm{~ns}$ ) to the presence of air. 

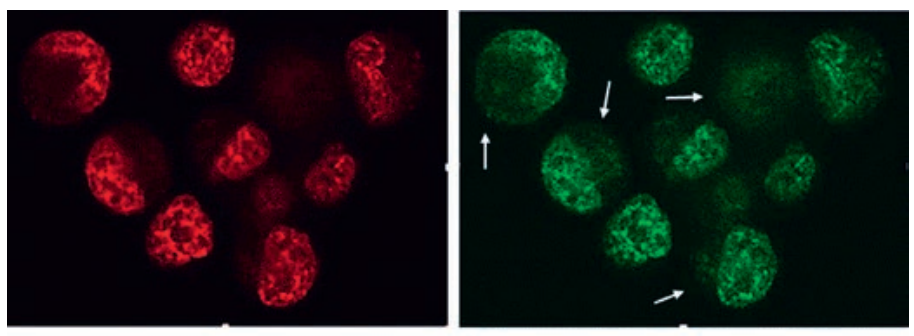

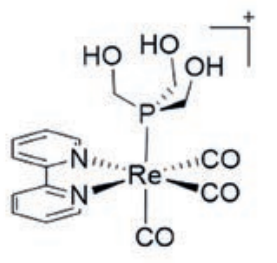

$\lambda_{\max }{ }^{\mathrm{em}}=515 \mathrm{~nm}$
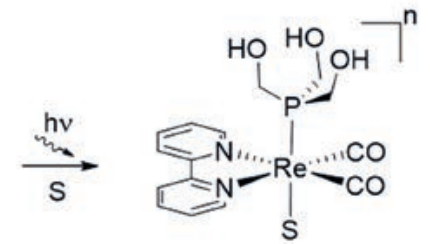

$\lambda_{\max }{ }^{\mathrm{em}}=585 \mathrm{~nm}$
Fig. 7. Confocal fluorescence microscopy images of PPC-1 cells incubated with fac- $\left[\mathrm{Re}(\mathrm{bpy})(\mathrm{CO})_{3}\left(\mathrm{PR}_{3}\right)\right]^{+}$complex (where $\left.\mathrm{R}=\mathrm{CH}_{2} \mathrm{OH}\right)$. Left: image collected with minimal photolysis from the $405 \mathrm{~nm}$ (red, $\lambda_{\mathrm{em}}=$ 465-495 nm). Right: image collected after $405 \mathrm{~nm}$ photolysis (green, $\lambda_{\text {em }}>660 \mathrm{~nm}$ ). Figure readapted with permission of Publisher. ${ }^{[52]}$

The similar type of ligand arrangement and coordination geometry was used as a blueprint for boosting the photochemical reactivity towards $\mathrm{CO}$ release of related species (Fig. 8). Hernández Mejías et al. have recently described a tricarbonyl rhenium complex that incorporates a phosphine moiety and a pyridyltriazole bidentate ligand, which upon irradiation in the near-UV range, undergoes fast photoreaction. ${ }^{[53]}$ Alike the phosphanetriyltrimethanol complex of Pierri, the effective photochemical release of CO is associated with distinct optical variations of the emission properties, with the emitted light shifting from green to orange-red for the solvated photoproduct. This photoreaction is linear within the first 2 min of irradiation, indicating a first-order photoreaction with a rate constant close to $0.033 \mathrm{~s}^{-1}$. In this type of complexes, pyridyl-triazole ligand isomerism has a significant influence on the electronic properties of the molecules. ${ }^{[54]}$ Depending on the geometric orientation of the benzo[ $[d]$ oxazole unit, the emitted phosphorescence in organic solvents shows distinct colours and intensities, indicating that grafting a non-coordinated $\pi$-conjugated fragment on the 1,2,4-triazole group can be a strategy for the design of efficient light-emitting materials, and for possibly discerning different biological targets of the molecules. It is worth mentioning that without the phosphine ligand closely related $\mathrm{Re}$ complexes are photo-inactive towards $\mathrm{CO}$ release. ${ }^{[55]}$

The groups of Wilson and Mascharak have described other prominent examples of photoreactive anticancer Re complexes (Fig. 8). Chakraborty prepared 1,3,5-triaza-7-phosphaadamantane species exhibiting moderate $\mathrm{CO}$ release upon irradiation with low-power UV light, and exploited their inherent luminescence to follow their cellular internalization in human breast cancer cells and to assess cell viability upon photoactivation. ${ }^{[56]}$ The tris(hydroxymethyl)phosphine and 1,4-diacetyl-1,3,7-triaza-5-phosphabicylco[3.3.1]nonane phenathroline species of Marker undergo photosubstitution of a CO ligand while at the same time sensitising the formation of ${ }^{1} \mathrm{O}_{2}$ with quantum yields as high as $70 \%$. ${ }^{[32]}$ These compounds show minimal toxicity in the absence of light, but act as photoactivated anticancer agents against different cancer cell lines, including cisplatin-resistant ovarian strains. The phototoxic response is associated with the release of both CO, the rhenium-containing photoproduct, as well as the production of ${ }^{1} \mathrm{O}$. Singlet oxygen, or reactive oxygen species formation is a feature known for other Re complexes exhibiting triplet-based luminescence ${ }^{[57]}$ and was exploited by Frey for the preparation of

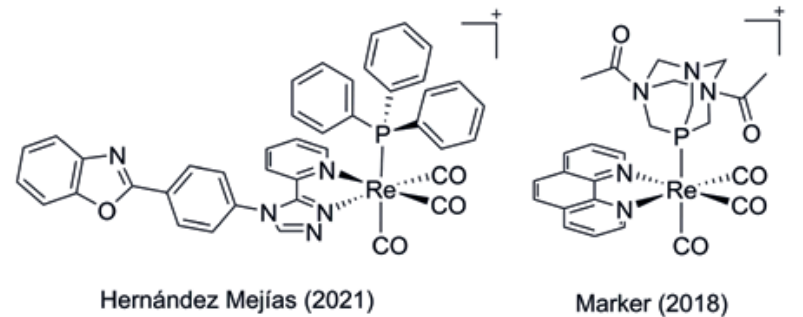

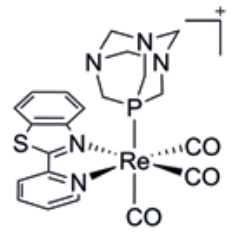

Chakraborty (2017)

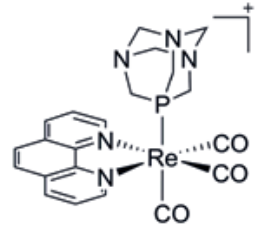

Chakraborty (2017)
Fig. 8. Structures of photoreactive tricarbonyl rhenium complexes bearing $\pi$-accepting phosphine ancillary ligands.

bisquinoline rhenium tricarbonyl-type complexes acting as antibacterial agents against Gram-positive and Gram-negative bacteria as well as drug-resistant strains. ${ }^{[50 \mathrm{~g}]}$

As mentioned in section 3, the possibility of activating $\mathrm{Re}$ tricarbonyl species towards photochemical substitution of $\mathrm{CO}$, is attributed to the stronger trans-labilising ability of the phosphorus donor of $\pi$-acid ligands. Light activation permits the forward internal conversion rate between the ${ }^{3}$ MLCT and thermally accessible higher energy photoexcited ${ }^{3} \mathrm{LF}$ state that is productive in terms of $\mathrm{CO}$ dissociation. In the last five years, however, several examples of diimine complexes bearing either $\sigma$ - or $\pi$-donating ancillary ligands active towards $\mathrm{CO}$ photo-substitution have been described (Fig. 9).[58] The group of Mascharak at UC Santa Cruz has been particularly active in the field. In 2016, Carrington described a water-containing $\operatorname{Re}(\mathrm{I})$ carbonyl complex derived from 2-(2-pyridyl)-benzothiazole capable of rapidly releasing CO under low-power UV illumination. ${ }^{[59]}$ The photoreaction is accompanied by a change in luminescence from orange to deep blue for the solvated photoproduct. These two distinct luminescence signals permitted to track the entry of the pro-drug complex into cancer cells and to monitor the $\mathrm{CO}$ (drug) delivery step within the target tissue. The same group introduced photoactive luminescent rhenium carbonyl complexes of phenathroline with $\sigma$ - or $\pi$-donors ancillary ligands. These species are able to deliver $\mathrm{CO}$ and eradicate either human breast adenocarcinoma cells, when administered molecularly, ${ }^{[60]}$ or human colorectal adenocarcinoma cells when grafted on a biocompatible carboxymethyl chitosan matrix. ${ }^{61]}$ The effects, attributed to CO delivery, are dose-dependent.

\section{Conclusions}

Rhenium diimine tricarbonyl complexes continue to be the focus of growing scientific interest because of their outstanding photophysical and photochemical properties, which find applications in the fields of catalysis, energy storage and medicine. In this short review, we have described the basic photophysical properties of the molecules that allow them to function as luminescent probes, and how the same properties permit the photochemical exploitation of the molecules in $e . g . \mathrm{H}_{2}$ production, photocatalysts in $\mathrm{CO}_{2}$ reduction and ligand substitution. We highlighted the most significant electronic transitions of these complexes, the orbitals involved, and the contribution of each ligand in determining both the luminescence features (e.g. lifetimes of emission, large Stokes shifts and resistance to photobleaching), the cellular localisation and the photo-reactivity of the molecules. The nature of the monodentate ligand often dictates the reactivity and mechanism of these 

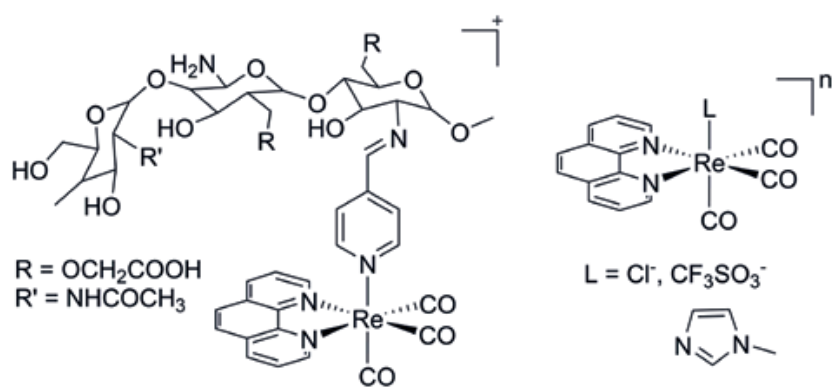

$\mathrm{L}=\mathrm{Cl}^{-}, \mathrm{CF}_{3} \mathrm{SO}_{3}{ }^{-}$

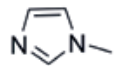

Chakraborty (2017)

Chakraborty (2017)
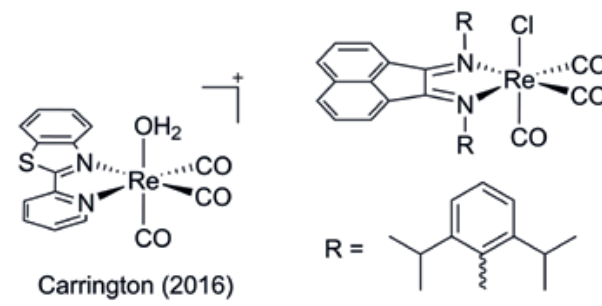

Kianfar (2015)

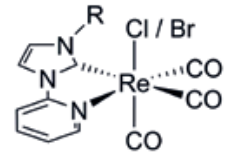

$\mathrm{R}=\mathrm{n}$-butyl, mesityl

Vaughan (2014)
Fig. 9. Structures of photoreactive tricarbonyl rhenium complexes bearing $\sigma$ - or $\pi$ - donating ancillary ligands.

photoactive compounds allowing room for further chemical research. In particular we have discussed how in the photochemical ligand substitution (PLS) reactions, trans-labilising effect of $\pi-$ acids is crucial for $\mathrm{CO}$ elimination under lower power incident radiation. The PLS reaction is currently being investigated as an alternative strategy for the preparation of new therapeutic agents and it is poised to have a great impact in design of rhenium "prodrugs'. This reaction, with the high photooxidising properties of the compounds, is anticipated to assist the realisation of new photodynamic therapeutics.

\section{Acknowledgements}

We are grateful to the Swiss National Science Foundation (Project\# 200021_196967) and the University of Fribourg for continuous support of our work.

Received: June 1, 2021

[1] a) K. Li, Y. Chen, J. Wang, C. Yang, Coord. Chem. Rev. 2021, 433, 213755, https://doi.org/10.1016/j.ccr.2020.213755; b) E. Baggaley, J. A. Weinstein, J. A. G. Williams, Coord. Chem. Rev. 2012, 256, 1762, https://doi.org/10.1016/j.ccr.2012.03.018; c) P.-Y. Ho, C.L. Ho, W.-Y. Wong, Coord. Chem. Rev. 2020, 413, 213267 , https://doi.org/10.1016/j.ccr.2020.213267.

[2] a) Q. Zhao, C. Huang, F. Li, Chem. Soc. Rev. 2011, 40, 2508, https://doi.org/10.1039/C0CS00114G; b) G. Li, C. Wu, D.L. Ma, C.-H. Leung, Trends Analyt. Chem. 2021, 139, 116270, https://doi.org/10.1016/j.trac.2021.116270.

[3] a) A. Anand, P. Singh, V. Kumar, G. Bhargava, RSC Adv. 2019, 9 , 25554, https://doi.org/10.1039/C9RA02839K; b) K. Urbina, D. Tresp, K. Sipps, M. Szostak, Adv. Synth. Catal. 2021, 363, 2723, https://doi.org/10.1002/adsc.202100116; c) D. Bhattacherjee, M. Rahman, S. Ghosh, A. K. Bagdi, G. V. Zyryanov, O. N. Chupakhin, P. Das, A. Hajra, Adv. Synth. Catal. 2021, 363, 1597, https://doi.org/10.1002/adsc.202001509.

[4] K. K.-W. Lo, Acc. Chem. Res. 2015, 48, 2985, https://doi.org/10.1021/acs.accounts.5b00211.

[5] S. Sato, O. Ishitani, Coord. Chem. Rev. 2015, 282, 50, https://doi.org/10.1016/j.ccr.2014.05.009.

[6] R. Baková, M. Chergui, C. Daniel, A. Vlćek, S. Záliš, Coord. Chem. Rev. 2011, 255, 975, https://doi.org/10.1016/j.ccr.2010.12.027.

[7] a) K. K.-W. Lo, A. W.-T. Choi, W. H.-T. Law, Dalton Trans. 2012, 41, 6021, https://doi.org/10.1039/C2DT11892K; b) K. K.-W. Lo, S. P.-Y. Li, RSC Adv. 2014, 4, 10560, https://doi.org/10.1039/C3RA47611A; c) Y. Chen, R. Guan, C. Zhang, J. Huang, L. Ji, H. Chao, Coord. Chem. Rev. 2016, 310, 16, https://doi.org/10.1016/j.ccr.2015.09.010; d) L. C.-C. Lee, K.-K. Leung, K. K.-W. Lo, Dalton Trans. 2017, 46, 16357, https://doi.org/10.1039/C7DT03465B.
[8] a) F. Ragone, H. c. H. M. Saavedra, P. M. D. Gara, G. T. Ruiz, E. Wolcan, J. Phys. Chem. A 2013, 117, 4428, https://doi.org/10.1021/jp402550g; b) A. Burchinov, V. Kiselev, A. Penni, V. Khistyaeva, Opt. Spectrosc. 2015, 119, 932, https://doi.org/10.1134/S0030400X15120073; c) L. D. Ramos, H. M. da Cruz, K. P. M. Frin, Photochem. Photobiol. Sci. 2017, 16, 459, https://doi.org/10.1039/C6PP00364H; d) R. M. Spada, M. Cepeda-Plaza, M. L. Gómez, G. n. Günther, P. Jaque, N. Pizarro, R. E. Palacios, A. s. Vega, J. Phys. Chem. C 2015, 119, 10148, https://doi.org/10.1021/acs.jpcc.5b01990.

[9] a) U. Schatzschneider, Inorg. Chim. Acta 2011, 374, 19, https://doi.org/10.1016/j.ica.2011.02.068; b) U. Schatzschneider, Br. J. Pharmacol. 2015, 172, 1638, https://doi.org/10.1111/bph.12688; c) R. D. Rimmer, A. E. Pierri, P. C. Ford, Coord. Chem. Rev. 2012, 256, 1509, https://doi.org/10.1016/j.ccr.2011.12.009; d) M. A. Gonzales, P. K. Mascharak, J. Inorg. Biochem. 2014, 133, 127, https://doi.org/10.1016/j.jinorgbio.2013.10.015; e) E. Kottelat, Z. Fabio, Inorganics 2017, 5, 24, https://doi.org/10.3390/inorganics5020024.

[10] A. Vogler, H. Kunkely, Coord. Chem. Rev. 2000, 200-202, 991 , https://doi.org/10.1016/S0010-8545(99)00241-6.

[11] S. R. Stoyanov, J. M. Villegas, A. J. Cruz, L. L. Lockyear, J. H. Reibenspies, D. P. Rillema, J. Chem. Theory Comput. 2005, 1, 95, https://doi.org/10.1021/ct049956g.

[12] R. A. Kirgan, B. P. Sullivan, D. P. Rillema, in: 'Photochemistry and Photophysics of Coordination Compounds II', 2007, 281, Ed. Balzani, Book_Doi 10.1007/978-3-540-73349-2.

[13] C. M. Marian, WIREs Comput. Mol. Sci. 2012, 2, 187 , https://doi.org/10.1002/wcms.83.

[14] A. J. Lees, Chem. Rev. 1987, 87, 711, https://doi.org/10.1021/cr00080a003.

[15] K. Koike, N. Okoshi, H. Hori, K. Takeuchi, O. Ishitani, H. Tsubaki, I. P. Clark, M. W. George, F. P. A. Johnson, J. J. Turner, J. Am. Chem. Soc. 2002, 124, 11448, https://doi.org/10.1021/ja017032m.

[16] S. Obara, M. Itabashi, F. Okuda, S. Tamaki, Y. Tanabe, Y. Ishii, K. Nozaki, M.-a. Haga, Inorg. Chem. 2006, 45, 8907, https://doi.org/10.1021/ic060796o.

[17] T. G. Kotch, A. J. Lees, S. J. Fuerniss, K. I. Papathomas, R. W. Snyder, Inorg. Chem. 1993, 32, 2570, https://doi.org/10.1021/ic00063a059.

[18] a) A. J. Lees, Comments Inorg. Chem. 1995, 17, 319, https://doi.org/10.1080/02603599508032711; b) D. J. Stufkens, Comments Inorg. Chem. 1992, 13, 359, https://doi.org/10.1080/02603599208048467; c) P. Chen, T. J. Meyer, Chem. Rev. 1998, 98, 1439, https://doi.org/10.1021/cr941180w.

[19] T. Morimoto, O. Ishitani, Acc. Chem. Res. 2017, 50, 2673, https://doi.org/10.1021/acs.accounts.7b00244.

[20] a) H. Tsubaki, S. Tohyama, K. Koike, H. Saitoh, O. Ishitani, Dalton Trans. 2005, 385, https://doi.org/10.1039/B407947G; b) H. Tsubaki, A. Sekine, Y. Ohashi, K. Koike, H. Takeda, O. Ishitani, J. Am. Chem. Soc. 2005, 127, 15544, https://doi.org/10.1021/ja053814u.

[21] A. Zarkadoulas, E. Koutsouri, C. Kefalidi, C. A. Mitsopoulou, Coord. Chem Rev. 2015, 304-305, 55, https://doi.org/10.1016/j.ccr.2014.11.006.

[22] a) Y. Kuramochi, O. Ishitani, H. Ishida, Coord. Chem. Rev. 2018, 373, 333, https://doi.org/10.1016/j.ccr.2017.11.023; b) K. A. Grice, C. P. Kubiak, in 'Adv. Inorg. Chem.', Vol. 66, Eds. M. Aresta, R. van Eldik, Academic Press, 2014, p. 163, https://doi.org/10.1016/B978-0-12-420221-4.000056; c) C. D. Windle, R. N. Perutz, Coord. Chem. Rev. 2012, 256, 2562, https://doi.org/10.1016/j.ccr.2012.03.010.

[23] A. Kumar, S. S. Sun, A. J. Lees, Top. Organomet. Chem. 2009, 29, 1 , https://doi,org/10.1007/3418_2009_2.

[24] H. Takeda, K. Koike, T. Morimoto, H. Inumaru, O. Ishitani, in 'Adv. Inorg. Chem.', Vol. 63, Eds. R. v. Eldik, G. Stochel, Academic Press, 2011, p. 137 https://doi.org/10.1016/B978-0-12-385904-4.00007-X.

[25] a) B. Probst, A. Rodenberg, M. Guttentag, P. Hamm, R. Alberto, Inorg. Chem. 2010, 49, 6453, https://doi.org/10.1021/ic100036v; b) B. Probst, M. Guttentag, A. Rodenberg, P. Hamm, R. Alberto, Inorg. Chem. 2011, 50, 3404, https://doi.org/10.1021/ic102317u; c) K. T. Oppelt, P. Hamm, Chimia 2021, 75, 188, https://doi.org/10.2533/chimia.2021.188.

[26] a) D. H. Gibson, H. He, Chem. Commun. 2001, 2082 https://doi.org/10.1039/B106270K; b) D. H. Gibson, X.Yin, Chem. Commun 1999, 1411, https://doi.org/10.1039/A902453K; c) D. H. Gibson, X. Yin, $J$. Am. Chem. Soc. 1998, 120, 11200, https://doi.org/10.1021/ja982284h; d) D H. Gibson, X. Yin, H. He, M. S. Mashuta, Organometallics 2003, 22, 337 , https://doi.org/10.1021/om020677q

[27] Y. Hayashi, S. Kita, B. S. Brunschwig, E. Fujita, J. Am. Chem. Soc. 2003 , 125, 11976, https://doi.org/10.1021/ja035960a.

[28] H. Takeda, K. Koike, H. Inoue, O. Ishitani, J. Am. Chem. Soc. 2008, 130, 2023, https://doi.org/10.1021/ja077752e.

[29] a) A. Nakada, O. Ishitani, ACS Catal. 2018, 8, 354, https://doi.org/10.1021/acscatal.7b03275; b) C. W. Machan, J. Yin, S. A. Chabolla, M. K. Gilson, C. P. Kubiak, J. Am. Chem. Soc. 2016, 138, 8184 https://doi.org/10.1021/jacs.6b03774; c) C. W. Machan, S. A. Chabolla, J. Yin, M. K. Gilson, F. A. Tezcan, C. P. Kubiak, J. Am. Chem. Soc. 2014 136, 14598, https://doi.org/10.1021/ja5085282; d) M. D. Sampson, J. D. Froehlich, J. M. Smieja, E. E. Benson, I. D. Sharp, C. P. Kubiak, Energy 
Environ. Sci. 2013, 6, 3748, https://doi.org/10.1039/C3EE42186D; e) J. A. Barrett, C. J. Miller, C. P. Kubiak, Trends Chem. 2021, 3, 176, https://doi.org/10.1016/j.trechm.2020.12.009.

[30] a) F. Zobi, Inorg. Chem. 2010, 49, 10370, https://doi.org/10.1021/ic101246a; b) F. Zobi, Inorg. Chem. 2009, 48, 10845, https://doi.org/10.1021/ic901223t.

[31] K. Koike, J. Tanabe, S. Toyama, H. Tsubaki, K. Sakamoto, J. R. Westwell, F. P. A. Johnson, H. Hori, H. Saitoh, O. Ishitani, Inorg. Chem. 2000, 39, 2777, https://doi.org/10.1021/ic9911901.

[32] S. C. Marker, S. N. MacMillan, W. R. Zipfel, Z. Li, P. C. Ford, J. J. Wilson, Inorg. Chem. 2018, 57, 1311, https://doi.org/10.1021/acs.inorgchem.7b02747.

[33] E. Kottelat, F. Lucarini, A. Crochet, A. Ruggi, F. Zobi, Eur. J. Inorg. Chem. 2019, 2019, 3758, https://doi.org/ 10.1002/ejic.201900568.

[34] S. Sato, A. Sekine, Y. Ohashi, O. Ishitani, A. M. Blanco-Rodríguez, A. Vlćek, T. Unno, K. Koike, Inorg. Chem. 2007, 46, 3531, https://doi.org/10.1021/ic0621603.

[35] a) J. Delasoie, N. Radakovic, A. Pavic, F. Zobi, Appl. Sci. 2020, 10, https://doi.org/10.3390/app10207380; b) S. Hostachy, C. Policar, N. Delsuc, Coord. Chem. Rev. 2017, 351, 172, https://doi.org/10.1016/j.ccr.2017.05.004; c) Z. Lam, K. V. Kong, M. Olivo, W. K. Leong, Analyst 2016, 141, 1569, https://doi.org/10.1039/C5AN02191J; d) L. Quaroni, M. Obst, M. Nowak, F. Zobi, Angew. Chem. Int. Ed. 2015, 54, 318, https://doi.org/10.1002/anie.201407728; e) G. Santoro, T. Zlateva, A. Ruggi, L. Quaroni, F. Zobi, Dalton Trans. 2015, 44, 6999 , https://doi.org/10.1039/c4dt03598d; f) C. Policar, J. B. Waern, M.-A. Plamont, S. Clède, C. Mayet, R. Prazeres, J.-M. Ortega, A. Vessières, A. Dazzi, Angew. Chem. Int. Ed. 2011, 50, 860, https://doi.org/10.1002/anie.201003161.

[36] a) K. K.-W. Lo, K. Y. Zhang, S. P.-Y. Li, Eur. J. Inorg. Chem. 2011, 2011, 3551, https://doi.org/10.1002/ejic.201100469; b) F. L. Thorp-Greenwood, Organometallics 2012, 31, 5686, https://doi.org/10.1021/om3004477.

[37] S. Clede, F. Lambert, R. Saint-Fort, M. A. Plamont, H. Bertrand, A. Vessieres, C. Policar, Chem. Eur. J. 2014, 20, 8714, https://doi.org/10.1002/chem.201402471.

[38] A. Leonidova, G. Gasser, ACS Chem. Biol. 2014, 9, 2180, https://doi.org/10.1021/cb500528c.

[39] L. Henry, N. Delsuc, C. Laugel, F. Lambert, C. Sandt, S. Hostachy, A.-S. Bernard, H. C. Bertrand, L. Grimaud, A. Baillet-Guffroy, C. Policar, Bioconjugate Chem. 2018, 29, 987, https://doi.org/10.1021/acs.bioconjchem.7b00825.

[40] L. Raszeja, A. Maghnouj, S. Hahn, N. Metzler-Nolte, ChemBioChem 2011, 12, 371, https://doi.org/10.1002/cbic.201000576.

[41] a) M.-W. Louie, M. Ho-Chuen Lam, K. Kam-Wing Lo, Eur. J. Inorg. Chem. 2009, 2009, 4265, https://doi.org/10.1002/ejic.200900518; b) K. K.W. Lo, M.-W. Louie, K.-S. Sze, J. S.-Y. Lau, Inorg. Chem. 2008, 47, 602, https://doi.org/10.1021/ic701675c.

[42] K. Yin Zhang, K. Ka-Shun Tso, M.-W. Louie, H.-W. Liu, K. K.-W. Lo, Organometallics 2013, 32, 5098, https://doi.org/ 10.1021/om400612f.

[43] M.-W. Louie, H.-W. Liu, M. H.-C. Lam, Y.-W. Lam, K. K.-W. Lo, Chem. Eur. J. 2011, 17, 8304, https://doi.org/10.1002/chem.201101399.

[44] a) A. J. Amoroso, M. P. Coogan, J. E. Dunne, V. Fernández-Moreira, J. B. Hess, A. J. Hayes, D. Lloyd, C. Millet, S. J. A. Pope, C. Williams, Chem. Commun. 2007, 3066, https://doi.org/10.1039/B706657K; b) A. J. Amoroso, R. J. Arthur, M. P. Coogan, J. B. Court, V. Fernández-Moreira, A. J. Hayes, D. Lloyd, C. Millet, S. J. A. Pope, New J. Chem. 2008, 32, 1097, https://doi.org/10.1039/B802215A

[45] R. G. Balasingham, M. P. Coogan, F. L. Thorp-Greenwood, Dalton Trans. 2011, 40, 11663, https://doi.org/10.1039/C1DT11219H.

[46] a) P. J. Wright, S. Muzzioli, M. V. Werrett, P. Raiteri, B. W. Skelton, D. S. Silvester, S. Stagni, M. Massi, Organometallics 2012, 31, 7566, https://doi.org/10.1021/om300870a; b) M. V. Werrett, P. J. Wright, P. V. Simpson, P. Raiteri, B. W. Skelton, S. Stagni, A. G. Buckley, P. J. Rigby, M. Massi, Dalton Trans. 2015, 44, 20636, https://doi.org/10.1039/C5DT03470A.

[47] a) C. A. Bader, R. D. Brooks, Y. S. Ng, A. Sorvina, M. V. Werrett, P. J. Wright, A. G. Anwer, D. A. Brooks, S. Stagni, S. Muzzioli, M. Silberstein, B. W. Skelton, E. M. Goldys, S. E. Plush, T. Shandala, M. Massi, RSC Adv. 2014, 4, 16345, https://doi.org/10.1039/C4RA00050A; b) C. A. Bader, E. A. Carter, A. Safitri, P. V. Simpson, P. Wright, S. Stagni, M. Massi, P. A. Lay, D. A. Brooks, S. E. Plush, Mol. BioSyst. 2016, 12, 2064, https://doi.org/10.1039/C6MB00242K; c) J. L. Wedding, H. H. Harris, C. A. Bader, S. E. Plush, R. Mak, M. Massi, D. A. Brooks, B. Lai, S. Vogt, M. V. Werrett, P. V. Simpson, B. W. Skelton, S. Stagni, Metallomics 2016, 9, 382, https://doi.org/10.1039/c6mt00243a \%J Metallomics.

[48] C. A. Bader, A. Sorvina, P. V. Simpson, P. J. Wright, S. Stagni, S. E. Plush, M. Massi, D. A. Brooks, FEBS Lett. 2016, 590, 3051, https://doi.org/10.1002/1873-3468.12365.

[49] a) J. Delasoie, P. Schiel, S. Vojnovic, J. NikodinovicRunic, F. Zobi, Pharmaceutics 2020, 12, 480, https://doi.org/10.3390/pharmaceutics12050480; b) J. Delasoie, A. Pavic, N.
Voutier, S. Vojnovic, A. Crochet, J. Nikodinovic-Runic, F. Zobi, Eur. J. Med. Chem. 2020, 204, 112583, https://doi.org/10.1016/j.ejmech.2020.112583; c) J. Rossier, D. Hauser, E. Kottelat, B. Rothen-Rutishauser, F. Zobi, Dalton Trans. 2017, 46, 2159, https://doi.org/10.1039/c6dt04443c; d) P. Collery, D. Desmaele, V. Vijaykumar, Curr. Pharm. Des. 2019, 25, 1, http://dx.doi.org/10.2174/1381612825666190902161400; e) E. B. Bauer, A. A. Haase, R. M. Reich, D. C. Crans, F. E. Kühn, Coord. Chem. Rev 2019, 393, 79, https://doi.org/10.1016/j.ccr.2019.04.014; f) C. C. Konkankit, S. C. Marker, K. M. Knopf, J. J. Wilson, Dalton Trans. 2018, 47, 9934, https://doi.org/10.1039/c8dt01858h.

[50] a) S. N. Sovari, S. Vojnovic, S. S. Bogojevic, A. Crochet, A. Pavic, J Nikodinovic-Runic, F. Zobi, Eur. J. Med. Chem. 2020, 205, 112533 , https://doi.org/10.1016/j.ejmech.2020.112533; b) S. Nasiri Sovari, F. Zobi, Chemistry 2020, 2, 418, https://doi.org/10.3390/chemistry2020026; c) M. Patra, M. Wenzel, P. Prochnow, V. Pierroz, G. Gasser, J. E. Bandow, N. Metzler-Nolte, Chem. Sci. 2015, 6, 214 , https://doi.org/10.1039/c4sc02709d; d) M. Wenzel, M. Patra, C. H. Senges, I. Ott, J. J. Stepanek, A. Pinto, P. Prochnow, C. Vuong, S. Langklotz, N. Metzler-Nolte, J. E. Bandow, ACS Chem. Biol. 2013, 8, 1442, https://doi.org/10.1021/cb4000844; e) D. Siegmund, N. Lorenz, Y. Gothe, C. Spies, B. Geissler, P. Prochnow, P. Nuernberger, J. E. Bandow, N. MetzlerNolte, Dalton Trans. 2017, 46, 15269, https://doi.org/10.1039/c7dt02874a; f) A. Frei, Antibiotics 2020, 9, 90, https://doi.org/10.3390/antibiotics9020090; g) A. Frei, M. Amado, M. A. Cooper, M. A. T. Blaskovich, Chem. Eur. J. 2019, 26, 2852, https://doi.org/10.1002/chem.201904689.

[51] a) G. Santoro, R. Beltrami, E. Kottelat, O. Blacque, A. Y. Bogdanova, F. Zobi, Dalton Trans. 2016, 45, 1504, https://doi.org/10.1039/c5dt03402g; b) F. Zobi, Future Med. Chem. 2013, 5, 175, https://doi.org/10.4155/Fmc.12.196; c) F. Zobi, O. Blacque, R. A. Jacobs, M. C. Schaub, A. Y. Bogdanova, Dalton Trans. 2012, 41, 370, https://doi.org/10.1039/c1dt10649j; d) F. Zobi, A. Degonda, M. C. Schaub, A. Y. Bogdanova, Inorg. Chem. 2010, 49, 7313, https://doi.org/10.1021/ic100458j.

[52] A. E. Pierri, A. Pallaoro, G. Wu, P. C. Ford, J. Am. Chem. Soc. 2012, 134, 18197, https://doi.org/10.1021/ja3084434.

[53] Á. D. Hernández Mejías, A. Poirot, M. Rmili, N. Leygue, M. Wolff, N. Saffon-Merceron, E. Benoist, S. Fery-Forgues, Dalton Trans. 2021, 50 , 1313, https://doi.org/10.1039/D0DT03577G

[54] J. Wang, B. Delavaux-Nicot, M. Wolff, S. Mallet-Ladeira, R. Métivier, E. Benoist, S. Fery-Forgues, Dalton Trans. 2018, 47, 8087, https://doi.org/10.1039/C8DT01120F

[55] A. M. Mansour, Eur. J. Inorg. Chem. 2018, 2018, 4805 , https://doi.org/10.1002/ejic.201801055.

[56] I. Chakraborty, S. J. Carrington, G. Roseman, P. K. Mascharak, Inorg. Chem. 2017, 56, 1534, https://doi.org/10.1021/acs.inorgchem.6b02623.

[57] a) A. Leonidova, V. Pierroz, R. Rubbiani, J. Heier, S. Ferrari, G. Gasser, Dalton Trans. 2014, 43, 4287, https://doi.org/10.1039/c3dt51817e; b) R.-R. Ye, C.-P. Tan, M.-H. Chen, L. Hao, L.-N. Ji, Z.-W. Mao, Eur. J. Inorg. Chem 2016, 22, 7800, https://doi.org/10.1002/chem.201505160; c) R.-R. Ye, C.P. Tan, Y.-N. Lin, L.-N. Ji, Z.-W. Mao, Chem. Commun. 2015, 51, 8353 , https://doi.org/10.1039/C5CC02354H.

[58] a) S. B. Jiménez-Pulido, N. A. Illán-Cabeza, F. Hueso-Ureña, C. R. Maldonado, P. Sánchez-Sánchez, M. P. Fernández-Liencres, M. FernándezGómez, M. N. Moreno-Carretero, Dalton Trans. 2016, 45, 15142, https://doi.org/10.1039/C6DT02208A; b) E. Kianfar, C. Schäfer, M. R. Lornejad-Schäfer, E. Portenkirchner, G. Knör, Inorg. Chim. Acta 2015, 435, 174, https://doi.org/10.1016/j.ica.2015.05.035; c) J. G. Vaughan, B. L. Reid, P. J. Wright, S. Ramchandani, B. W. Skelton, P. Raiteri, S. Muzzioli, D. H. Brown, S. Stagni, M. Massi, Inorg. Chem. 2014, 53, 3629, https://doi.org/10.1021/ic403138a.

[59] S. J. Carrington, I. Chakraborty, J. M. L. Bernard, P. K. Mascharak, Inorg. Chem. 2016, 55, 7852, https://doi.org/10.1021/acs.inorgchem.6b00511.

[60] I. Chakraborty, J. Jimenez, W. M. C. Sameera, M. Kato, P. K. Mascharak, Inorg. Chem. 2017, 56, 2863, https://doi.org/10.1021/acs.inorgchem.6b02999.

[61] I. Chakraborty, J. Jimenez, P. K. Mascharak, Chem. Commun. 2017, 53, 5519, https://doi.org/10.1039/c7cc02842c.

\section{License and Terms}

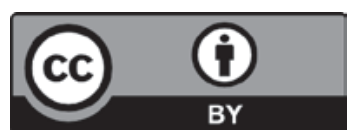

This is an Open Access article under the terms of the Creative Commons Attribution License CC BY 4.0. The material may not be used for commercial purposes.

The license is subject to the CHIMIA terms and conditions: (http:// chimia.ch/component/sppagebuilder/?view=page\&id=12).

The definitive version of this article is the electronic one that can be found at https://doi.org/10.2533/chimia.2021.837 